\title{
Fabrication of U-10 wt.\%Zr Metallic Fuel Rodlets for Irradiation Test in BOR-60 Fast Reactor
}

\author{
Ki-Hwan Kim, Jong-Hwan Kim, Seok-Jin Oh, Jung-Won Lee, \\ Ho-Jin Lee, and Chan-Bock Lee \\ Next Generation Fuel Division, Korea Atomic Energy Research Institute, Daejeon 305-353, Republic of Korea \\ Correspondence should be addressed to Jong-Hwan Kim; jhk9@kaeri.re.kr
}

Received 12 June 2016; Accepted 14 August 2016

Academic Editor: Hyeong-Yeon Lee

Copyright (C) 2016 Ki-Hwan Kim et al. This is an open access article distributed under the Creative Commons Attribution License, which permits unrestricted use, distribution, and reproduction in any medium, provided the original work is properly cited.

The fabrication technology for metallic fuel has been developed to produce the driver fuel in a PGSFR in Korea since 2007. In order to evaluate the irradiation integrity and validate the in-reactor of the starting metallic fuel with FMS cladding for the loading of the metallic fuel, U-10 wt.\%Zr fuel rodlets were fabricated and evaluated for a verification of the starting driver fuel through an irradiation test in the BOR-60 fast reactor. The injection casting method was applied to U-10 wt.\%Zr fuel slugs with a diameter of $5.5 \mathrm{~mm}$. Consequently, fuel slugs per melting batch without casting defects were fabricated through the development of advanced casting technology and evaluation tests. The optimal GTAW welding conditions were also established through a number of experiments. In addition, a qualification test was carried out to prove the weld quality of the end plug welding of the metallic fuel rodlets. The wire wrapping of metallic fuel rodlets was successfully accomplished for the irradiation test. Thus, PGSFR fuel rodlets have been soundly fabricated for the irradiation test in a BOR-60 fast reactor.

\section{Introduction}

KAERI seeks to develop and demonstrate the technologies needed to transmute the long-lived transuranic actinide isotopes in spent nuclear fuel into shorter-lived fission products, thereby dramatically decreasing the material volume requiring disposal, the long-term radiotoxicity, and the heat load of high-level waste sent to a geological repository $[1,2]$. A prototype Gen IV sodium-cooled fast reactor (PGSFR) is being developed in combination with the pyroelectrochemical processing of spent fuel in KAERI [3]. It can solve the problem of the accumulation of pressurized water reactor (PWR) spent fuel and can increase the utilization of uranium resources while maintaining a higher proliferation resistance. The pyroprocessing of light water reactor (LWR) spent fuel extracts uranium and transuranium (TRU) and separates fission products for disposal [4-6]. Extracted uranium and TRU are used to fabricate the metallic fuel. Pyroprocessing on the spent metallic fuel of a sodium-cooled fast reactor (SFR) can also extract uranium and TRU for recycling in an SFR after separating fission products. Extracted uranium and TRU are used to fabricate the metallic fuel.
As the fuel for the Generation-IV SFR, metallic fuel was selected to meet the targets of the Generation-IV reactor such as the economy, safety, sustainability, and proliferation resistance [7-10]. For sustainability and proliferation resistance, long-lived minor actinides (MA) such as $\mathrm{Np}, \mathrm{Am}$, and $\mathrm{Cm}$ are transmuted in the reactor [11, 12]. To enhance the economy, the fuel is irradiated up to a high burnup. Metallic fuel has noble compatibility with a sodium reactor coolant, which guarantees a level of flexibility and margin during reactor operation. The higher thermal conductivity of metallic fuel and the adoption of the fuel design with a sodium fuel gap can keep the fuel temperature low during irradiation. Therefore, SFR using metallic fuel can be operated with passive safety, which implies that the fuel integrity is maintained during transients without support of an active reactor cooling system. Pyroelectrochemical processing of LWR spent fuels extracts uranium and TRU and separates fission products for disposal. The recovered uranium and TRU are then used to fabricate the metallic fuel, U-TRU$\mathrm{Zr}$. The technical challenges of U-TRU-Zr fuel are the fuel fabrication and irradiation performance up to a high burnup. 

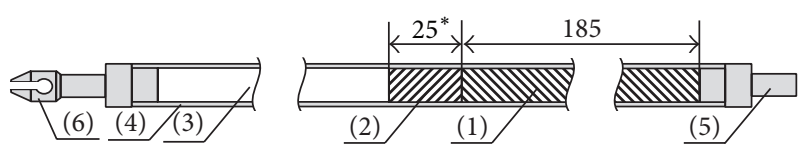

Longitudinal cross-section of BOR-60 fuel rod
(1) Fuel slug
(4) Cladding
(2) Sodium
(5) Bottom end plug
(3) Gas plenum
(6) Top end plug

FIgURE 1: A schematic diagram of the fuel rodlets for the irradiation test in BOR-60 fast reactor.

Metallic fuels, such as U-Zr and U-TRU-Zr alloys, have been considered as a nuclear fuel for an SFR related to the closed fuel cycle for managing minor actinides and reducing the amount of spent nuclear fuel since the 1980s $[13,14]$. Metallic fuel has advantages such as simple fabrication procedures, good neutron economy, high thermal conductivity, excellent compatibility with a Na coolant, and inherent passive safety [15-17]. The reference fuel for a PGSFR being developed by KAERI is metallic alloy. U-10 wt.\%Zr metallic fuel has been considered a starting driver fuel for a PGSFR in Korea. Metallic fuel slugs are encapsulated by the cladding tube. The fuel gap between the fuel slug and cladding is filled with sodium to enhance the heat transport. A wire is wrought on the outer surface of the fuel rodlet to maintain the gap between fuel rodlets to allow the sodium coolant to flow.

In order to evaluate the irradiation integrity and validate the in-reactor of the starting metallic fuel with FMS cladding for the loading of the metallic fuel, an irradiation test will be performed in a BOR-60 fast reactor. In this study, U$10 \mathrm{wt} . \% \mathrm{Zr}$ metallic fuel rodlets have been fabricated and evaluated for the fuel verification of the starting driver fuel.

\section{Experimental}

Figures 1 and 2 show a schematic diagram of the fuel rodlets for the irradiation test and a fabrication flow chart of metallic fuel rodlets for irradiation testing in a BOR-60 fast reactor, respectively. A fuel rodlet consists of a fuel slug, a cladding tube, and end plugs. The fuel slug is contained in the cladding tube where sodium is charged in between. The fuel slug is made of U-10 wt.\%Zr alloy with a length of $185 \mathrm{~mm}$. The cladding tube with a diameter of $7.5 \mathrm{~mm}$ is fabricated with ferritic-martensitic steel. Sodium is covered up to the level of $25 \mathrm{~mm}$ higher than the upper end of the fuel slugs.

Elemental lumps of low enrichment uranium (LEU) and sponges of $\mathrm{Zr}$ were used to fabricate $\mathrm{U}-10 \mathrm{wt} . \% \mathrm{Zr}$ fuel slugs. The enrichment of the U-235 was $19.9 \mathrm{wt} . \%$. The total content of impurities such as $\mathrm{Al}, \mathrm{B}, \mathrm{C}, \mathrm{Ca}, \mathrm{Cd}, \mathrm{Li}, \mathrm{Si}, \mathrm{Sn}$, and $\mathrm{W}$ is lower than $600 \mathrm{ppm}$. The size of a $\mathrm{Zr}$ sponge is from 0.8 to $25.4 \mathrm{~mm}$ and the purity of $\mathrm{Zr}$ element is $99.5 \mathrm{wt} . \%$. To prevent the interaction behavior between the fuel melt and graphite crucible, a $\mathrm{Y}_{2} \mathrm{O}_{3}$ slurry-coated graphite crucible was used for the melting of the fuel slugs [18]. A $\mathrm{Y}_{2} \mathrm{O}_{3}$ slurry-sprayed method was also applied to coat all of the molds. A vacuum injection casting method was applied to fabricate $\mathrm{U}-10 \mathrm{wt} . \% \mathrm{Zr}$ fuel slugs using an induction melting furnace. The U-10 wt.\% Zr fuel slugs were cast by upward filling the melt, utilizing the pressure difference between the outside and inside of the quartz mold. Casting experiments have been performed to optimize the casting process parameters such as pressurization pressure, casting temperature, mold preheating, and immersion time of the molds in the melt. The optimum casting conditions were established by repeated experiments on the casting process parameters. The injection casting equipment was evacuated at up to $10^{-3}$ torr and heated at $100^{\circ} \mathrm{C} / \mathrm{min}$ to the melting temperature, $1600^{\circ} \mathrm{C}$, through induction heating. Inert argon gas, which is stored in the accumulator tank adjacent to the casting furnace, was used to force the fuel melt into the molds. The fabricated slugs were removed from the mold pallet in a glove box after casting. The fuel loss was evaluated by measuring the material balance before and after the casting. The soundness of the fuel slugs was examined by gamma-ray radiography and immersion density measurements. The fuel slugs were cut into slices of suitable thickness using a slowspeed $\mathrm{SiC}$ abrasive cut-off wheel for performing the metallographic test. The microstructures and compositions were analyzed using a scanning electron microscope (SEM) and an energy dispersive X-ray spectroscope (EDX). Chemical analyses were also carried out to confirm the actual compositions of the fuel slugs and other impurities using inductively coupled plasma atomic emission spectrometry (ICP-AES).

The sodium bonding process has been applied in a glove box under argon atmosphere to prevent the interaction between sodium and oxygen or between sodium and moisture. The oxygen and moisture content have been controlled at under $5 \mathrm{ppm}$ in the glove box after the adjustment of the integrated operation conditions. The sodium bonding process consists of four steps: charging the sodium and fuel slug into the cladding tube jacket, top-end plug welding, melting down the sodium metal, and applying bonding between the sodium and cladding tube in the fuel rodlet by heating and mechanical impact. The major process parameters were the melting temperature, heating rate, loading sequence of the fuel slug and sodium, and the impact method. The sodium level and defects, and the slug position of the sodium-bonded fuel rodlets, were examined through X-ray radiography attached with computer tomography (CT).

There are many commercialized welding techniques such as gas tungsten arc welding (GTAW), electron beam welding (EBW), and laser beam welding (LBW) as a sort of fusion welding and resistance upset butt welding, percussion welding, and flash welding as a sort of solid state welding [19]. Among them, resistance upset butt welding is now used for the end plug welding of PWR fuel elements and CANDU fuel rods in a commercial basis. The GTAW method should be selected as the end plug welding method in consideration of the weldability, weld joint design, and production efficiency. The GTAW technology was adopted and the welding joint design was improved to fabricate the metallic fuel rodlets. The optimal welding parameters were also adjusted through a number of experiments. The end plug welding of the SFR fuel rodlet is a special process, and the welding quality should be verified through the qualification test according to the Quality Assurance Program (QAP) and the regulation Korea 


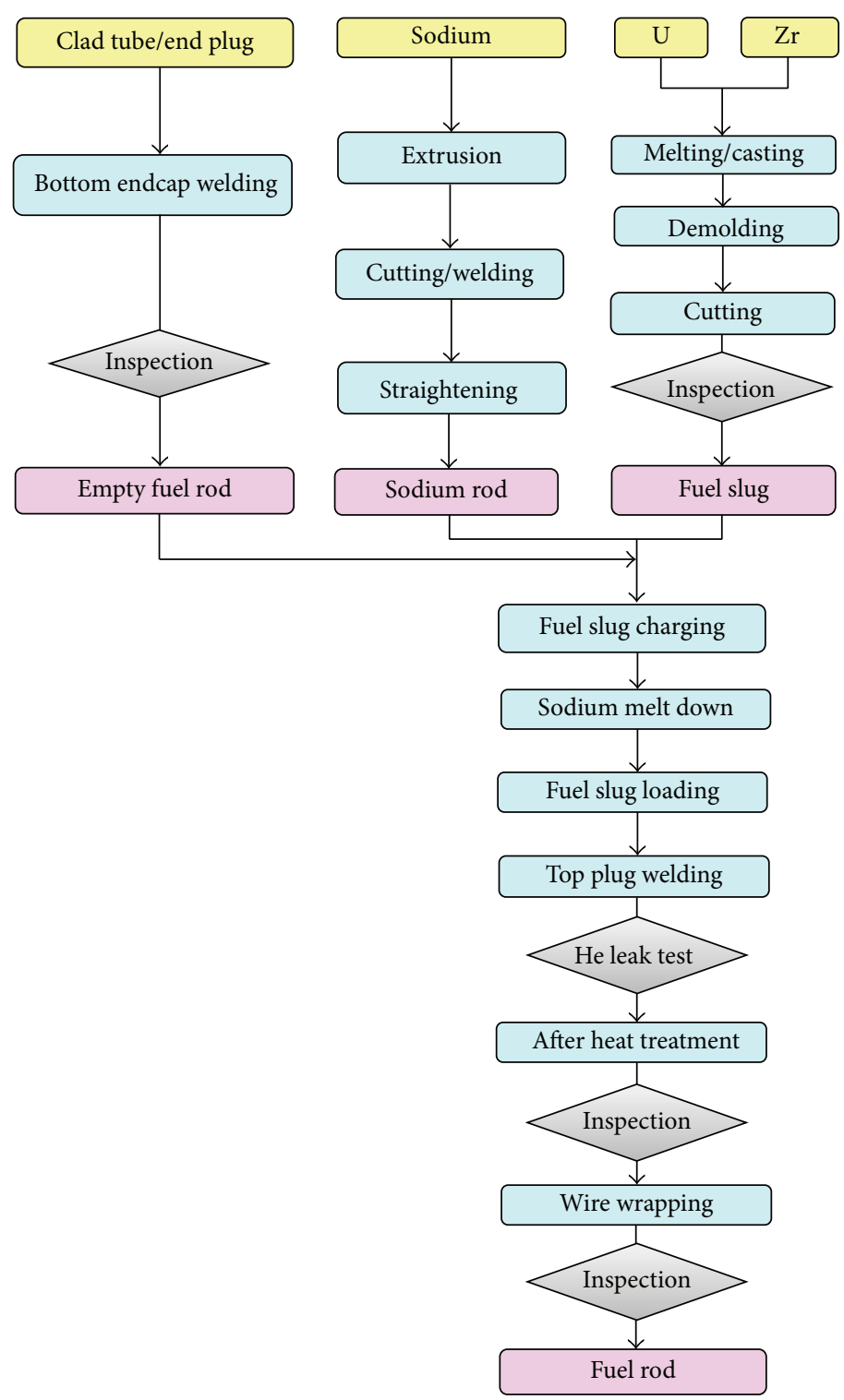

FIGURE 2: Fabrication flow chart of metallic fuel rods for irradiation test in BOR-60 fast reactor.

Electric Power Industry Code (KEPIC). The cladding tubes and end plugs for the BOR-60 test fuel were prepared by machining with ferrite-martensitic steel (FMS) materials. End plug welding is conducted in the welding chamber with a GTAW welder in a He gas atmosphere. The welding chamber accommodates the weld joint part and is evacuated by a vacuum pump to remove any air gas and is back-filled with He gas with a high purity of $99.999 \%$ to fill the inner space of the fuel rodlet. Based on the developed welding technology, welding equipment, welding conditions, and parameters, the qualification test was carried out to prove the weld quality of end plug welding of the metallic fuel rodlets. Based on the Inspection and Testing Plan (ITP), the weld quality evaluation tests such as a visual inspection of the weldment, X-ray radiography, helium leak test, metallographic examination, closed-end burst test, and dimension measurement were conducted to evaluate the weld quality of the end plug welding.
Post-weld heat treatment is conducted in the heat treatment chamber with a tube furnace in a vacuum atmosphere higher than $10^{-4}$ torr. The heat treatment chamber accommodates the fuel rodlets, but only the weld part is heated up to the target temperature of $730^{\circ} \mathrm{C}$ for $20 \mathrm{~min}$. A microhardness test was conducted using a Vickers microhardness tester.

A wire wrapping machine was manufactured horizontally to wind the fuel rodlets with HT-9 wire using a weight with a constant tension. Fusion balls of $1.5 \mathrm{~mm}$ in diameter were made using a tungsten inert gas (TIG) spot welder at both wire ends. The wrapping quality such as the fusion ball diameter and position, clearance between the wrapped and rodlet surface, and the twist pitch length were controlled through the control of the wrapping process conditions. A pitch length of the HT-9 wire, a gap distance between the wire and fuel rodlet, and the diameter of the fused ball were inspected using Vernier calipers, a thickness gauge, and an SEM. 


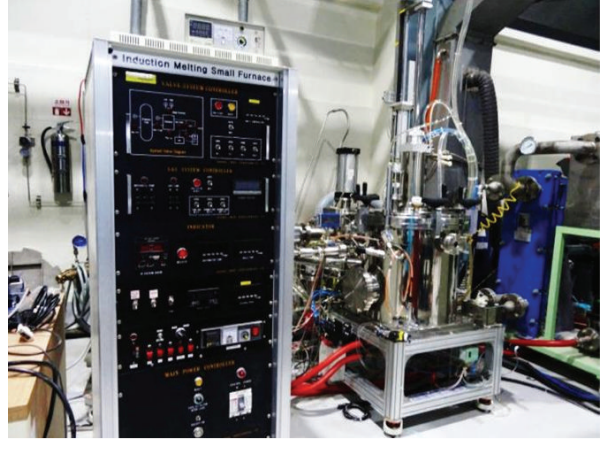

(a)

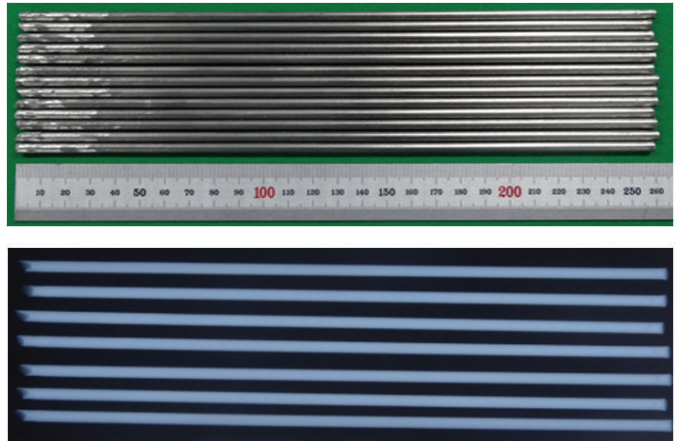

(b)

FIGURE 3: (a) Injection casting furnace and (b) image of fuel slugs (upper) and gamma-ray radiography (lower) of U-10 wt.\%Zr fuel slugs.

TABLE 1: The alloy composition of U-10 wt.\%Zr fuel slugs prepared by injection casting method.

\begin{tabular}{|c|c|c|c|c|c|c|}
\hline \multirow{2}{*}{ Position } & \multicolumn{6}{|c|}{ Content } \\
\hline & U (wt.\%) & $\mathrm{Zr}$ (wt.\%) & $\mathrm{Si}(\mathrm{ppm})$ & $\mathrm{C}(\mathrm{ppm})$ & $\mathrm{O}(\mathrm{ppm})$ & $\mathrm{N}(\mathrm{ppm})$ \\
\hline Upper & 88.4 & 10.3 & 102 & 250 & 800 & 140 \\
\hline Bottom & 89.3 & 10.4 & 497 & 40 & 1220 & 120 \\
\hline
\end{tabular}

\section{Results and Discussion}

U-10 wt.\%Zr fuel slugs fabricated with an injection casting furnace (Figure 3(a)) are shown in Figure 3(b). Thirteen fuel slugs with a diameter of $5.5 \mathrm{~mm}$ and a length of $260 \mathrm{~mm}$ were fabricated per melting batch. The reproducibility of the injection casting process has been drastically improved with precise temperature control and the stabilization of the melting and casting temperature through proportional-integralderivative (PID) control during injection casting. The gravity direction was from right to left in the photography. The surface at the upper region of the slugs was smooth, whereas the lower region, which was heated by an immersed hightemperature melt during the casting process, was significantly rough. However, the as-cast fuel slugs were generally sound with the full length of the quartz mold without significant casting defects. The gamma-ray radiography of the fabricated fuel slugs was performed to detect internal defects such as cracks and pores (Figure 3(b)). The internal defects were not detected in the fuel slugs.

The quantitative chemical composition by ICP-AES was investigated in the lower, middle, and upper positions of the U-10 wt.\%Zr slugs, as shown in Table 1 . The diameter of the fuel slugs meets the quality criteria of the tolerance of within $0.1 \mathrm{~mm}$ in an as-cast state. The $\mathrm{Zr}$ content of the $\mathrm{U}-10 \mathrm{wt} . \% \mathrm{Zr}$ fuel slugs matches the target composition well with only a slight variation of within $0.5 \mathrm{wt} . \%$, thus satisfying the quality criterion of the fuel slugs. The density of the U-10Zr fuel slugs was considerably uniform within the ranges of $\pm 0.3 \mathrm{~g} / \mathrm{cm}^{3}$ along the longitudinal direction of the fuel slug, as shown in Table 2. The fuel slugs were also sound without significant casting defects such as large pore and shrinkage, as shown in Figure 3(b). The result of the density measurement suggests
TABLE 2: The variations of the density according to the location of U-10 wt. $\%$ Zr fuel slugs.

\begin{tabular}{lccc}
\hline Location & Upper & Middle & Bottom \\
\hline Density $\left(\mathrm{g} / \mathrm{cm}^{3}\right)$ & 15.7 & 15.8 & 15.8 \\
\hline
\end{tabular}

that the $\mathrm{Zr}$ concentration is uniform throughout the fuel slug. The concentration of silicon, which is a constituent of the quartz mold used to cast the slug, was lower than $500 \mathrm{ppm}$ in the U-10Zr fuel; however, the total impurities of oxygen, carbon, nitrogen, and silicon were less than 2,000 ppm for the UZr fuel slugs, which satisfy the impurity criterion tentatively set based on the EBR-II fuel. This criterion was set based on the fact that the common impurities have a stronger affinity for $\mathrm{Zr}$. It was confirmed by $\gamma$-scanner that the relative deviation of the U-235 content along the axial direction was satisfied with $100 \pm 5 \%$. Figure 4 shows a scanning electron micrograph and energy-dispersive electron X-ray spectroscopy of U-10 wt.\%Zr alloy cast using an injection casting method, respectively. Dispersion phases, similar to the fuel slugs fabricated by gravity casting, were composed of $\mathrm{Zr}$-rich phases such as $\mathrm{UZr}_{2}$ or $\mathrm{Zr}$ particulates of about $5 \mathrm{~mm}$ in size. The matrix was also composed of a laminar structure in $0.2 \mu \mathrm{m}$ in thickness, similar to the microstructure of the fuel slugs cast into the graphite mold by gravity casting method [20]. The quality of the fuel slugs for the irradiation test was verified through a quality inspection.

Sodium bonding has been performed before the top-end plug welding. Quality inspections such as defect and pore verification, sodium level check, slug position check, and measuring procedure were performed after sodium bonding. 


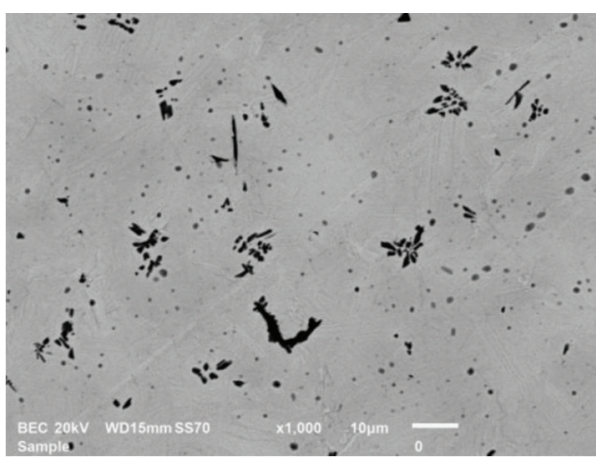

(a)

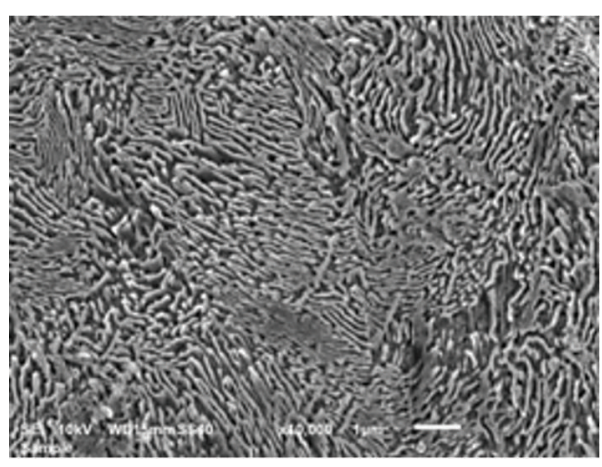

(b)

Figure 4: The microstructure of U-10 wt.\%Zr fuel slugs; (a) $\times 1000$ and (b) $\times 10000$.

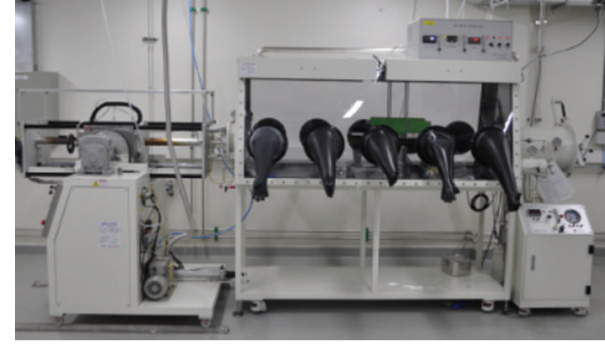

(a)

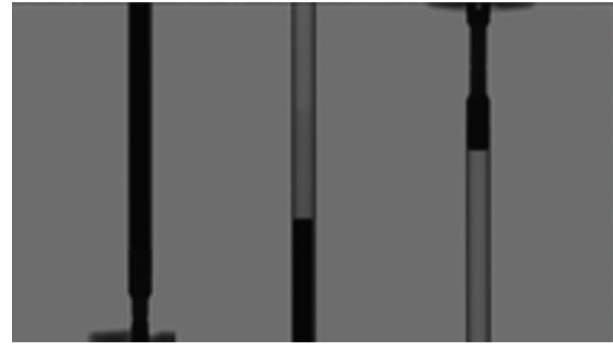

(b)

FIgURE 5: (a) Sodium melting/bonding equipment and (b) image of the X-ray defect measurement.

As a result of the X-ray radiography, the sodium level was from $22.27 \mathrm{~mm}$ to $27.87 \mathrm{~mm}$, and sodium defects such as a gas pore and bubble were not detected between the fuel slug and cladding tube. All fuel slugs settled down on the bottom end plug in a normal state, as shown in Figure 5. The improved sodium bonding method can significantly increase the yield of the quality inspection.

Based on the modification of the GTAW welding equipment and the adjustment of optimal welding conditions, the fuel rodlets were prepared using welding parameters such as a stick-out of $0.7 \mathrm{~mm}$, weld current of $30 \mathrm{~A}$, and rotation speed of $30 \mathrm{rpm}$. The weldments of the fuel rodlets looked sound with a visual inspection. It was revealed using an optical microscope that the sound weld region was similar to or larger than the thickness of cladding tube, $0.5 \mathrm{~mm}$. The end plug of the tube weld had a tensile strength equal to or greater than that of the tube material. A burst fracture occurred at the FMS cladding tube away from weldments in a closed-end burst test. The microhardness test result satisfied the specification of higher than $350 \mathrm{~kg} / \mathrm{mm}^{2}$. The helium gas filled in an inner space of a fuel rodlet was analyzed through gas mass spectrometry. A mole fraction of helium content of 99.6\% at atmospheric pressure was shown. The helium leak rate of the fuel rodlets was $4.3 \times 10^{-10} \mathrm{mbar} \cdot \ell / \mathrm{s}$, which is much less than the limit of the leak rate, $5 \times 10^{-7} \mathrm{mbar} \cdot \ell / \mathrm{s}$.

As a result of the qualification test, the weld quality of the end closure welding of SFR metallic fuel rodlet was qualified, and the welding process can be ready to produce SFR metallic fuel rodlets under the qualified conditions. On the basis of the qualification results, SFR fuel rodlets for the irradiation test were soundly manufactured by satisfying the ITP under the QAP. All of the plug end weld quality satisfies the design specifications, as shown in Figure 6.

The integrity of the fusion ball was inspected using a tensile test with a failure at the bent wire not at the fusion ball. The wire wrapping of the fuel rods was soundly fabricated for the irradiation test in a BOR-60 fast reactor, as shown in Figure 7.

\section{Summary}

The injection casting method was applied to metallic U$10 \mathrm{wt} . \% \mathrm{Zr}$ fuel slugs with a diameter of $5.5 \mathrm{~mm}$. Consequently, fuel slugs per melting batch without casting defects were fabricated through the development of an advanced casting technology and evaluation tests. Sodium bonding has been performed with the improved method, followed by the Xray radiography for the inspection of the sodium level and sodium defects. The optimal GTAW welding conditions and parameters were also established through a number of experiments. In addition, a qualification test was carried out to prove the weld quality of the end plug welding of the metallic fuel rodlets. The wire wrapping of metallic fuel rodlets for the irradiation test was soundly accomplished in KAERI. Thus, PGSFR fuel rodlets for the irradiation test in 


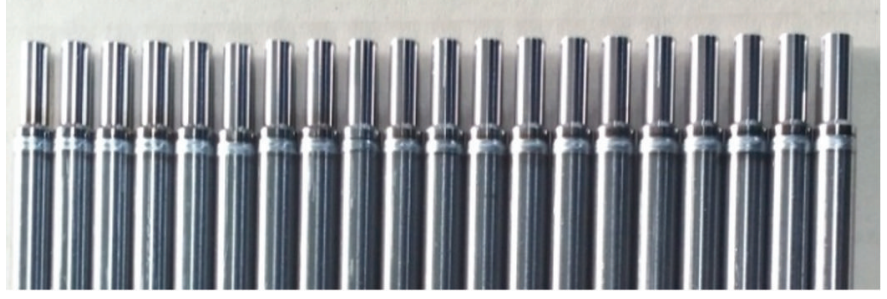

(a)

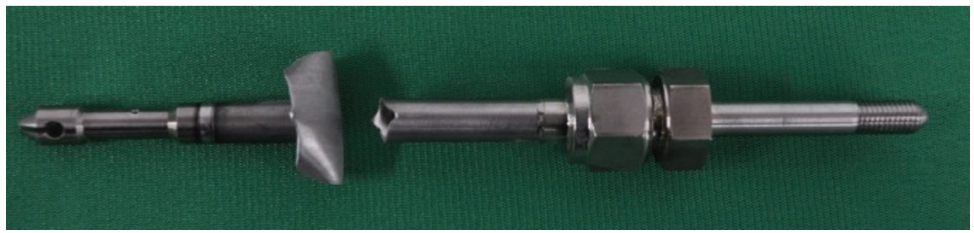

(c)

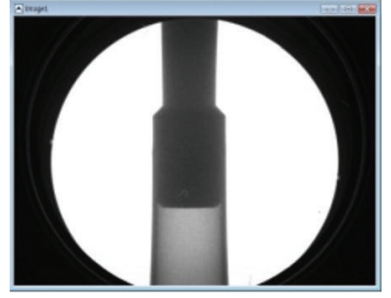

(b)

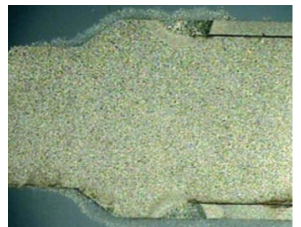

(d)

Figure 6: (a) Fuel rodlets welded by GTAW, (b) X-ray radiography on the weld part, (c) burst test result, and (d) a metallographic examination on the weld part.

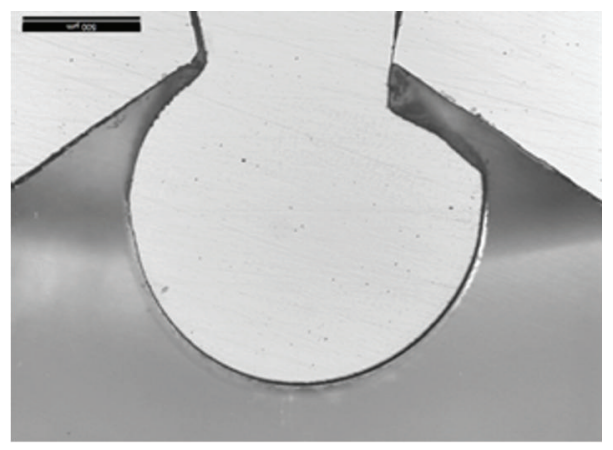

(a)

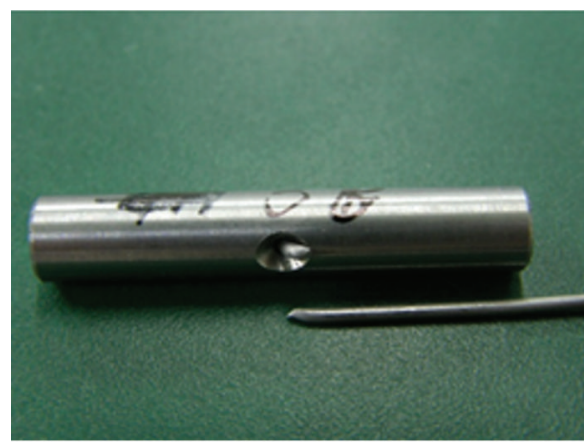

(b)
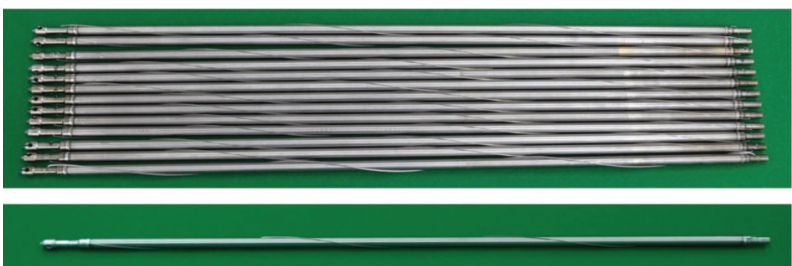

(c)

FIGURE 7: (a) Microstructure image of a fusion ball, (b) ruptured region after tensile test, and (c) wire wrapped rodlets for the irradiation test.

a BOR-60 fast reactor have been soundly fabricated for the fuel verification of the starting driver fuel.

\section{Competing Interests}

The authors declare that there are no competing interests regarding the publication of this paper.

\section{Acknowledgments}

This study was supported by the Fuel Cycle Research and Development Program funded by the U.S. Department of
Energy and the National Nuclear R\&D Program of the Ministry of Science and Technology (MOST) of Korea.

\section{References}

[1] H. Lee, G.-I. Park, J.-W. Lee et al., "Current status of pyroprocessing development at KAERI," Science and Technology of Nuclear Installations, vol. 2013, Article ID 343492, 11 pages, 2013.

[2] H. Lee, G. I. Park, and E. H. Kim, "Pyroprocessing technology development at KAERI," Nuclear Engineering and Technology, vol. 43, no. 4, pp. 317-328, 2011.

[3] C. Kim, D. Hartanto, and Y. Kim, "Uranium enrichment reduction in the prototype gen-IV sodium-cooled fast reactor 
(PGSFR) with PBO reflector," Nuclear Engineering and Technology, vol. 48, no. 2, pp. 351-359, 2016.

[4] J.-H. Jang, H.-S. Kang, Y.-S. Lee, H. S. Lee, and J.-G. Kim, "Development of continuous ingot casting process for uranium dendrites in pyroprocess," Journal of Radioanalytical and Nuclear Chemistry, vol. 295, no. 3, pp. 1743-1751, 2013.

[5] I. S. Kim, C. S. Seo, H. S. Shin, Y. S. Hwang, and S. W. Park, "Characteristics of reduced metal from spent oxide fuel by lithium," Journal of the Korean Nuclear Society, vol. 35, no. 4, pp. 309-317, 2003.

[6] Y. H. Kang, J. H. Lee, S. C. Hwang, J. B. Shim, E. H. Kim, and S. W. Park, "Electrodeposition characteristics of uranium by using a graphite cathode," Carbon, vol. 44, no. 14, pp. 3142-3145, 2006.

[7] C. E. Stevenson, The EBR-II Fuel Cycle Story, American Nuclear Society, La Grange Park, Ill, USA, 1987.

[8] J. H. Kittel, B. R. T. Frost, J. P. Mustelier, K. Q. Bagley, G. C. Crittenden, and J. Van Dievoet, "History of fast reactor fuel development," Journal of Nuclear Materials, vol. 204, pp. 1-13, 1993.

[9] T. Abram and S. Ion, "Generation-IV nuclear power: a review of the state of the science," Energy Policy, vol. 36, no. 12, pp. 43234330, 2008.

[10] L. C. Walters, B. R. Seidel, and J. H. Kittel, "Performance of metallic fuels and blankets in liquid-metal fast breeder reactors," Nuclear Technology, vol. 65, no. 2, pp. 179-231, 1984.

[11] Generation IV International Forum, A Technology Roadmap for Generation IV Nuclear Energy Systems, Generation IV International Forum, 2002.

[12] IAEA and OECD, Uranium 2007: Resources, Production and Demand, 2008.

[13] C. L. Trybus, "Injection casting of U-Zr-Mn, surrogate alloy for U-Pu-Zr-Am-Np," Journal of Nuclear Materials, vol. 224, article 305, 1995.

[14] J.-H. Kim, K.-H. Kim, and C.-B. Lee, "Preparation of U-Zr$\mathrm{Mn}$, a surrogate alloy for recycling fast reactor fuel," Advances in Materials Science and Engineering, vol. 2015, Article ID 131704, 8 pages, 2015.

[15] L. C. Walters and G. L. Hofman, "Metallic fast reactor fuels: a comprehensive treatment," Materials Science and Technology A, vol. 10, pp. 1-43, 1994.

[16] G. L. Hofman, L. C. Walters, and T. H. Bauer, "Metallic fast reactor fuels," Progress in Nuclear Energy, vol. 31, no. 1-2, pp. 83110, 1997.

[17] D. C. Crawford, D. L. Porter, and S. L. Hayes, "Fuels for sodium-cooled fast reactors: US perspective," Journal of Nuclear Materials, vol. 371, no. 1-3, pp. 202-231, 2007.

[18] J.-H. Kim, H. Song, K.-H. Kim, and C.-B. Lee, "Protective yttria coatings of melting crucible for metallic fuel slugs," Surface and Interface Analysis, vol. 47, no. 3, pp. 301-307, 2015.

[19] S.-S. Kim, G.-I. Park, J.-W. Lee, J.-H. Koh, and C.-H. Park, "Effect of heat on the soundness of zircaloy-4 end cap closure using a resistance upset welding," Journal of Nuclear Science and Technology, vol. 47, no. 3, pp. 262-268, 2010.

[20] K.-H. Kim, S.-J. Oh, S.-K. Kim, C.-T. Lee, and C.-B. Lee, "Microstructural characterization of U-Zr alloy fuel slugs for sodium-cooled fast reactor," Surface and Interface Analysis, vol. 44, no. 11-12, pp. 1515-1518, 2012. 

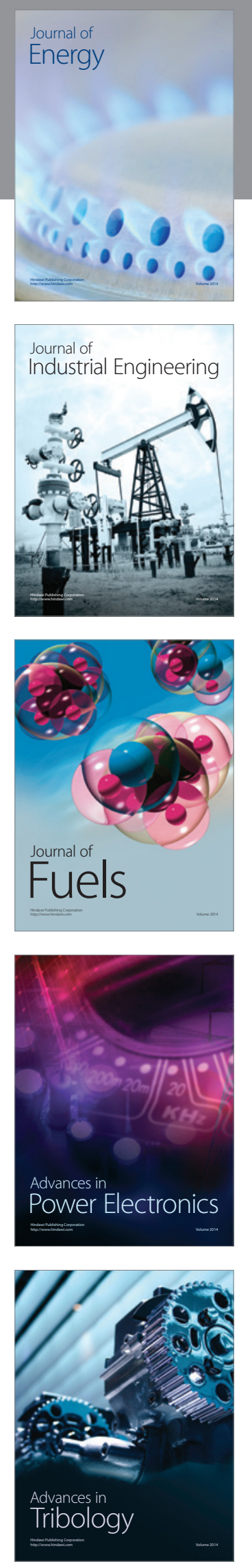
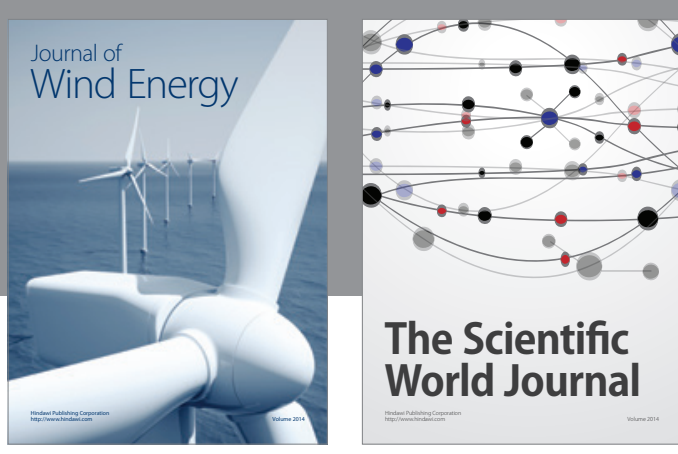

The Scientific World Journal
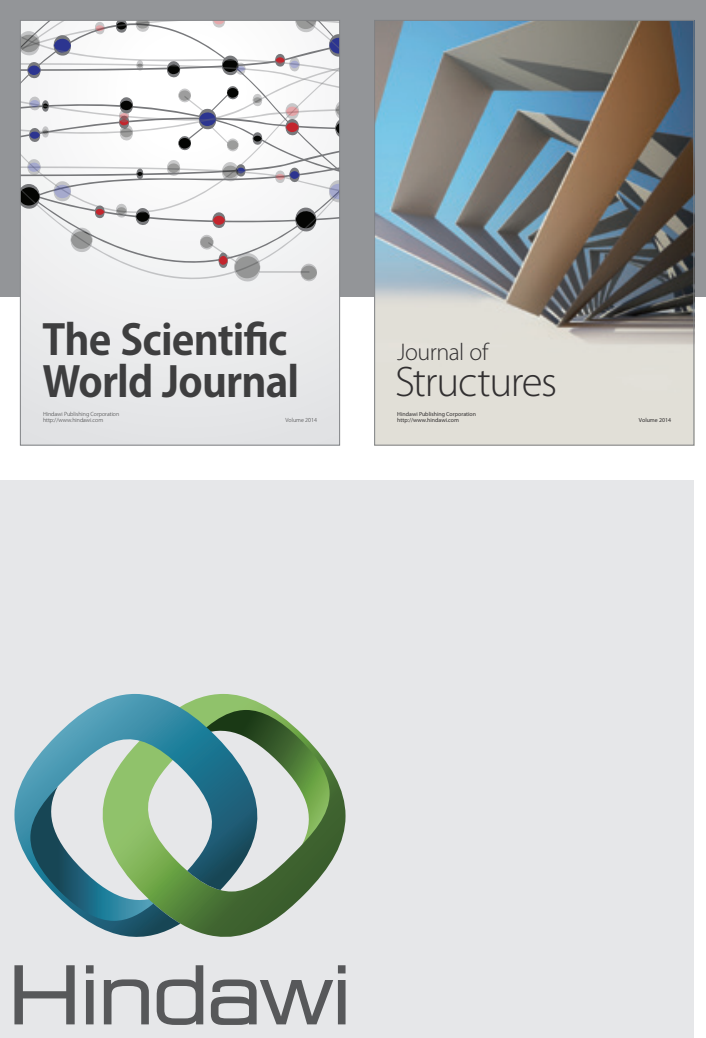

Submit your manuscripts at

http://www.hindawi.com
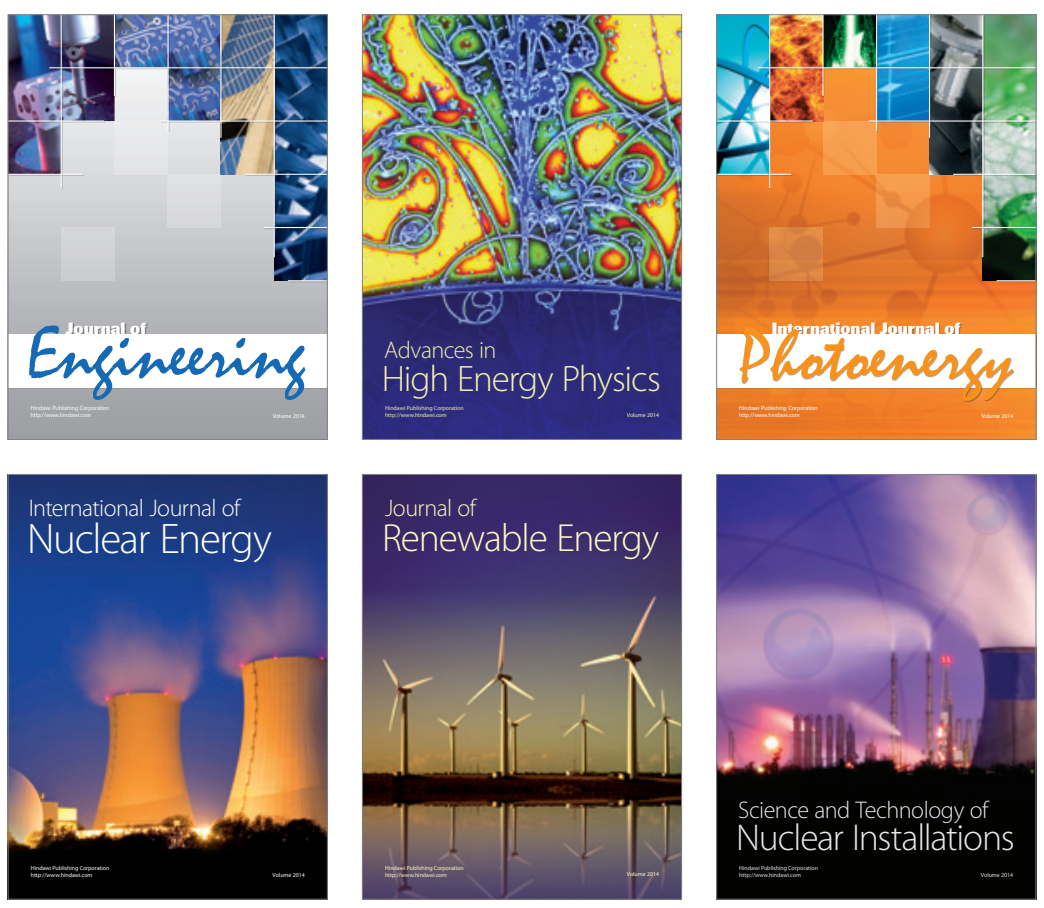
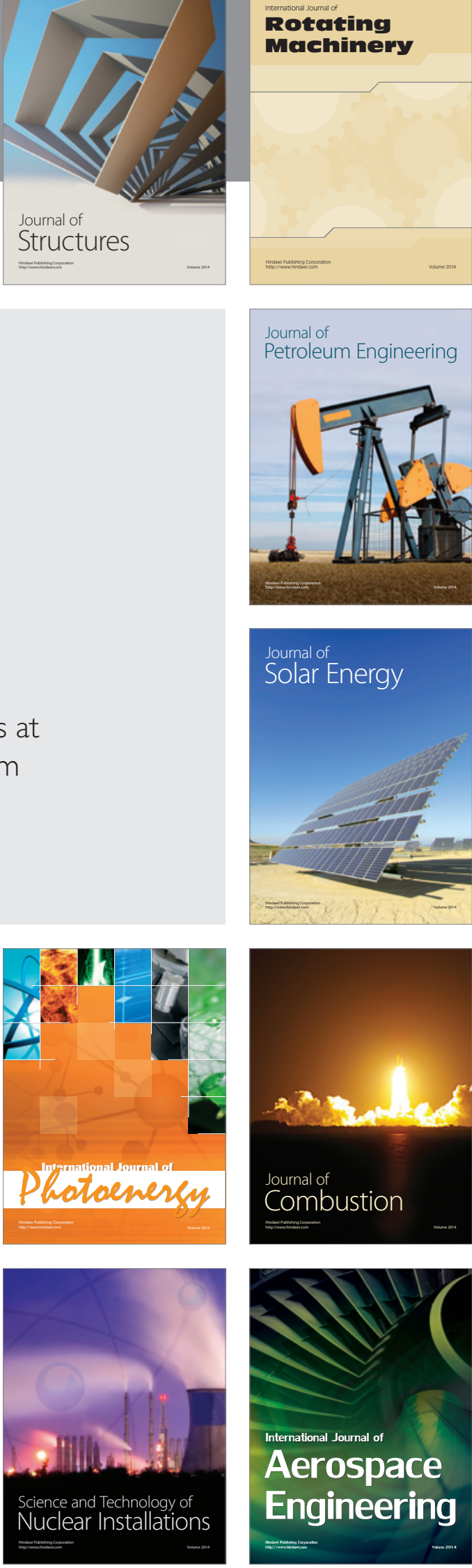